\title{
HBSS
}




\section{Country: Greece}

\section{Group: Hellenic Breast Surgical Society (HBSS)}

Address: $\quad$ 6, Eslin St.

11523 ATHENS

GREECE

Tel: +302106468180

Fax: +3021064 48140

Email: exem@hol.gr

Chair: C. Markopoulos

Department of Surgery

Athens University Medical School

8 lassiou St.

11521 ATHENS

GREECE

Tel: + 302107221413

Fax: + $302107247168 / 6199943$

Email: cmarkop@hol.gr

Centers: H. Gogas

Department of Medical Oncology

24 Karneadou St.

10675 ATHENS

GREECE

Tel: +30 6944681159 (mobile)

Fax: +30 2107781517

Email: hgogas@hol.gr

K. Dardoufas

Department of Radiotherapy - Oncology

19 Filota St.

THRAKOMAKEDONES 13676

GREECE

Tel: +302102431091

Fax: +302102435013

Email: codar@hol.gr

T. Philipidis

Consultant Pathologist

18-20 Tsoxa St.

11521 ATHENS

GREECE

Tel: +302106436039 


$\begin{array}{ll}\text { General } & \text { A. Polychronis } \\ \text { Secretary: } & \text { Consultant Surgeon } \\ & 9 \text { Ravine St. } \\ & \text { 11521 ATHENS } \\ & \text { GREECE } \\ & \text { Tel: }+302107225577\end{array}$

Website: www.exem.gr 